\title{
O CENTRALISMO FISCAL DA FEDERAÇÃO BRASILEIRA, POLÍTICAS PÚBLICAS MUNICIPAIS E SEU FINANCIAMENTO POR MEIO DO FUNDO DE PARTICIPAÇÃO DOS MUNICÍPIOS: UMA ANÁLISE DO RECURSO EXTRAORDINÁRIO 705.423
}

\author{
Gilson José Julião ${ }^{1}$
}

Resumo

O presente artigo consiste em uma análise empírica do Recurso Extraordinário 705.423 julgado no Supremo Tribunal Federal que envolve a arrecadação do Imposto de Renda e do Imposto sobre Produtos Industrializados e o montante que deve ser repassado pela União aos municípios através do Fundo de Participação dos Municípios. Todos esses tributos são instrumentos de implementação de políticas públicas, e, partindo dessa premissa, analisa-se o impacto no Pacto Federativo nas situações de benefícios, incentivos e isenções fiscais destes tributos já que são estes os grandes responsáveis pelo financiamento do Fundo de Participação dos Municípios.

Palavras-chave: Centralismo Fiscal; Federação Brasileira; Políticas Públicas Municipais; Fundo de Participação dos Municípios; Recurso Extraordinário 705.423.

\section{THE FISCAL CENTRALISM OF THE BRAZILIAN FEDERATION, MUNICIPAL PUBLIC POLICIES AND THEIR FINANCING THROUGH THE MUNICIPAL PARTICIPATION FUND: AN ANALYSIS OF THE EXTRAORDINARY RESOURCE 705.423}

\section{Summary}

This article consists of an empirical analysis of the Extraordinary Appeal 705,423 judged by the Federal Supreme Court, which involves the collection of Income Tax and Industrialized Products Tax and the amount that must be transferred by the Union to the municipalities through the Municipal Participation Fund. All these taxes are instruments for the implementation of public policies, and, based on this premise, the impact of the Federative Pact in situations of benefits, incentives and tax exemptions for these taxes is analyzed, since these are the main responsible for financing the Participation Fund Counties.

Keywords: Fiscal Centralism; Brazilian Federation; Municipal Public Policies; Municipal Participation Fund; Extraordinary Appeal 705.423.

\section{BREVE INTRODUÇÃO}

O presente artigo consiste em uma análise empírica do Recurso Extraordinário 705.423 julgado no Supremo Tribunal Federal (STF) que envolve a arrecadação do Imposto de Renda (IR) e do Imposto sobre Produtos Industrializados (IPI) e o montante que deve ser repassado

\footnotetext{
${ }^{1}$ Graduado em Direito (UNIFAVIP) e História (UEPB), especialista em Direito da Infância (UFRPE) e mestrando (PPGD-UNICAP). gilsonjuliao10@gmail.com.
} 
pela União aos municípios através do Fundo de Participação dos Municípios (FPM). Todos esses tributos são instrumentos de implementação de políticas públicas, e, partindo dessa premissa, analisa-se o impacto no Pacto Federativo nas situações de benefícios, incentivos e isenções fiscais destes tributos já que são estes os grandes responsáveis pelo financiamento do Fundo de Participação dos Municípios.

O problema de pesquisa se dará a partir da seguinte questão: de que modo a decisão do STF no Recurso Extraordinário 705.423, que gerou Repercussão Geral, afeta os municípios na execução de suas políticas públicas? Para responder a esta pergunta utilizaremos o mecanismo empírico metodológico através de "estudo de caso" que, segundo Robert Yin, é uma ferramenta que possibilita compreendermos os fenômenos sociais complexos e contemporâneos a partir de uma investigação que preserva questões significativas do contexto da vida real (YIN, 2001). Neste caso, os fenômenos sociais complexos e contemporâneos são a Repercussão Geral do Recurso Extraordinário 705.423 e o contexto da vida real são as políticas públicas que devem ser inseridas no seio da sociedade para que os seus direitos fundamentais sejam garantidos de forma efetiva.

Para isto, este trabalho será dividido em três partes, pois, antes da análise do Recurso Extraordinário 705.423, iremos tratar na primeira parte deste artigo sobre o centralismo fiscal da federação brasileira, na segunda parte falaremos sobre as políticas públicas no âmbito dos municípios brasileiros e seu financiamento através do Fundo de Participação dos Munícipios, ainda nesta segunda parte abordaremos o Imposto de Renda e o Imposto sobre Produtos Industrializados e por fim, na última parte desta pesquisa, analisaremos o Recurso Extraordinário 705.423.

Deste modo, entendemos que este artigo é relevante para aprofundar os estudos sobre o federalismo fiscal, as políticas públicas municipais, as repartições das competências tributárias e o seu reflexo no Fundo de Participação dos Municípios quando a União efetua políticas fiscais de concessão e isenções do IR e do IPI.

\section{O CENTRALISMO FISCAL DA FEDERAÇÃO BRASILEIRA}

Conforme demostrado em algumas pesquisas, o federalismos brasileiro é "procedente ao império", porém a forma federativa de estado só é adotada no Brasil com a Proclamação da 
República de 1889 (LIZIERO, 2017, p. 113), dando conformação jurídica à mesma por meio da Constituição de 1891 e mantendo tal forma de Estado desde então.

Dentro deste ínterim houve períodos de maior e menor centralização, mas somos sabedores que "o modelo federal brasileiro tem marcas de grande centralização e que é marcado por um longo processo em direção ao fortalecimento da União Federal em detrimento dos demais entes subnacionais" (CONCI, 2020, p. 50). Já com a primeira Carta Republicana houve um processo de descentralização em virtude da denominada "política dos governadores" que tinha o intuito de fortalecer as oligarquias locais. Mas, com o Getúlio Vargas no governo houve um período de grande concentração de poder na órbita federal, especialmente com a Constituição de 1937, inclusive com intervenção federal nos estados, porém, no plano fiscal, em 1934, houve uma partilha tributária em favor do munícipio que até então era dual, pois só fazia parte desta partilha a União e os estados. Pós-governo Vargas, em 1945, ocorre um novo retorno a um processo de descentralização dando-se aos estadosmembros e municípios autonomia, porém, com o golpe civil-militar de 1964 todo o processo de descentralização federativa cai por terra, enquanto o centralismo fiscal ganha corpo não tendo dúvidas sobre o poder fiscal da União Federal. Este período se estende até o processo Constituinte de 1987/1988, que a partir daí tem um movimento de fortalecimento de descentralização (CONCI, 2020).

Deste modo, mostraremos que a competência atinente à capacidade de produzir normas jurídicas referente à tributação mostra-se que existe um indicador da centralização no âmbito federal, ratificando, deste modo, que o centralismo fiscal da federação brasileira é observado por estudiosos como Leonan Liziero, que destaca que a "Constituição Federal de 1988 não aproveitou a oportunidade de galgar um novo modelo federativo, referente às distribuições fiscais" (LIZIERO, 2020, p. 133) e Conci que aborda que "o alto empoderamento fiscal da União Federal, por outro lado, impõe um excessivo fortalecimento de suas decisões, especialmente, em temas de políticas públicas, para as quais os entes subnacionais passam a ser mais seus executores que seus formuladores" (CONCI, 2020, p. $63)$.

Ainda nesta linha, Geilson Salomão Leite destaca que em matéria tributária existe no Brasil, nos últimos anos, "uma centralização no poder tributário cada vez maior nas mãos da União" (LEITE, 2013, p. 125). Além disto, o autor analisa que quando existe uma concessão 
de benefícios fiscais há em conjunto algumas ranhuras na harmonia federativa, isto ocorre devido o modelo de repartição de receitas instaurado na nossa Carta Maior. Em artigo sobre este tema, Denise Lucena Cavalcante e Raimundo Márcio Ribeiro Lima, registram que:

\footnotetext{
Inexiste pacto federativo cooperativo, ainda que permeado num engendrado sistema de repartição de competências e de receitas tributárias, quando existe ente federados num inevitável regime de sujeição financeira e, assim, corporificando intoleráveis obstáculos político-econômicos de transformação social por meio da prestação dos serviços públicos, tal como denuncia a parca qualidade e quantidade dos serviços públicos ofertados à sociedade pelos Municípios (CAVALCANTE; LIMA, 2015, p. 151).
}

Concluem, também que:

\begin{abstract}
A discussão sobre o federalismo fiscal não se limita à mera definição dum sistema de repartição fiscal, mas também sobre os encargos a serem suportados por cada ente político, ou seja, sobre o dimensionamento das competências administrativas e, consequentemente, o nível de descentralização na prestação dos serviços públicos (CAVALCANTE; LIMA, 2015, p. 152).
\end{abstract}

Um dos critérios para definir um Estado Federal perpassa pelo grau de autonomia das unidades subnacionais e de sua capacidade de elaborar suas respectivas normas tributarias. Essa autonomia é fundamental para demonstrar se determinado Estado é federal ou não. No Brasil, “observa-se, na figura do Município, como ente federado, a presença de uma ordem jurídica local, composta por ordenamento elaborado a partir do Poder Legislativo Municipal (...) sendo vedada (...) a discricionariedade na criação de tributos" (LIZIERO, 2020, p. 132). Neste sentido, a nossa Carta Maior define o espaço de liberdade, inovação e criatividade para que os Estados-membros, incluindo-se, neste caso, os municípios, possam legislar sobre a criação de tributos. Portanto, o centralismo fiscal tem seu escopo na própria Constituição como poderemos observar adiante.

As competências tributárias dos entes subnacionais se inclinam a reforçar a tendência vertical e centralizadora, pois, como demostraremos abaixo, a capacidade tributária dos estados e dos municípios são muito encurtadas na Carta de 1988. De acordo com a Constituição, em seu artigo 153, compete à União instituir impostos sobre sete tributos: importação de produtos estrangeiros (II); exportação, para o exterior, de produtos nacionais ou nacionalizados (IE); imposto de renda e proventos de qualquer natureza (IR); imposto 
sobre produtos industrializados (IPI); imposto sobre operações de crédito, câmbio e seguro (IOF); imposto sobre propriedade territorial rural (ITR); imposto sobre grandes fortunas (IGF). Este último através de lei complementar que, diga-se de passagem, ainda não foi regulamentado, mesmo nossa Carta Suprema já tendo completado 32 anos. Além dos sete citados, ainda é possível criar, norma de competência residual para imposto de qualquer natureza diversa das já citadas e também em eminência ou caso de guerra externa para se criar impostos extraordinários conforme prevê o artigo 154 da Constituição Federal.

Já aos estados cabem tributar sobre três impostos conforme prevê artigo 155 da CF: imposto sobre transmissão causa mortis e doação (ITMCD); imposto sobre circulação de mercadorias e serviços de transporte e de comunicação (ICMS); imposto sobre propriedade de veículos automotores (IPVA). Assim como nos estados, a competência tributaria dos munícipios, previstas no artigo 156, é bem reduzida, sendo apenas três: imposto predial e territorial urbano (IPTU); imposto sobre transmissão inter vivos de bens imóveis (ITBI); e o imposto sobre serviço (ISS).

Não se pode negar, dentro da lógica federativa do Estado Brasileiro, a importância do ente federal municipal que é consagrado em nossa Carta Maior, deste modo, entendemos que esta característica peculiar do modelo federativo do Brasil, da inclusão dos munícipios como entes federados, deve ser respeitada, pois o artigo primeiro e o dezoito da Constituição consagra que a República Federativa do Brasil é formada pela união indissolúvel dos Estados e Municípios como entes de organização político-admirativa autônomos.

Para José Afonso da Silva (1993) os municípios não detêm status de entidade federada, porém não corroboramos com este pensamento, pois assim como Tércio Sampaio Ferraz Junior, entendemos que:

Na Federação brasileira o Município é um ente público, político, que constitui a República Federativa (...). Trata-se de concepção normativa sui generis, posto que via de regra uma federação se constitui pela união dos Estados. A tradição brasileira, contudo, pela importância histórica do municipalismo na implantação da colônia, a unidade territorial Município, conquanto não represente no exercício político congressual (não há senadores municipais), constitui a federação brasileira (FERRAZ JUNIOR, 1992, p. 3074). 
Neste sentido, fica evidente que o federalismo adotado pelo Estado brasileiro na Carta Magna de 1988 é marcado pela presença fundamental dos municípios, portanto não há de se falar em federalismo e federação nos moldes do Brasil sem considerar a importância da municipalidade. Ainda nesta lógica, mas saindo do âmbito constitucional e indo para o campo sociológico, devemos destacar que são nas cidades que as pessoas vivem, moram, crescem, respiram, trabalham, se divertem, praticam suas atividades cotidianas e culturais (CERTEAU, 2014). Por isso a importância do município para a federação brasileira.

Para Raul Machado Horta (2003), os municípios são entidades federativas dotadas de autonomia e dentre estas se encontram a sua capacidade de produzir normas no campo financeiro. Esta possibilita que o ente municipal tenha capacidade de arrecadar recursos através de sua autonomia tributária essenciais para o desempenho de suas atribuições públicas que dentre elas está a de promover políticas públicas.

Como vimos, o constituinte de 1987/1988 reservou apenas três competências para instituir tributos no âmbito do município, esta competência reduzida faz com que os entes municipais não tenham capacidade de executar suas obrigações apenas com os recursos de seus tributos. Para isto, o mesmo constituinte reservou dispositivos constitucionais para a repartição das receitas oriundas dos tributos estaduais e da União para serem repartidos aos municípios.

Este dispositivo se encontra elencado nos artigos 158 e 159 da Constituição. Quanto aos repasses dos estados aos munícipios cabe a este: cinquenta por cento do que for arrecado do IPVA de veículos licenciados em seus territórios; vinte e cinco por cento sobre o ICMS. Já o montante que a União deve repartir com os munícipios são todo o produto arrecadado do IR que incidam sobre a fonte dos rendimentos pagos pelos munícipios e cinquenta por cento do ITR sobre os imóveis situados no município. Além destes, é devido aos municípios pela União, do montante de quarenta e nove por cento do IR, vinte e dois inteiros e cinco décimos por cento ao FPM e mais um por cento no primeiro decêndio no mês de dezembro e mais um por cento no mês de julho de cada ano.

Destarte, percebe-se que, embora exista uma repartição para os demais entes da Federação das receitas arrecadadas, não existe uma possibilidade para que os entes subnacionais, em especial os municípios, possam se autogerirem com o montante de tributos 
próprios. Portanto, percebemos que existe um centralismo fiscal no federalismo brasileiro no sentido de fortalecer o ente nacional.

\section{AS POLÍTICAS PÚBLICAS NO ÂMBITO DOS MUNICÍPIOS BRASILEIROS E SEU FINANCIAMENTO ATRAVÉS DO FUNDO DE PARTICIPAÇÃO DOS MUNÍCIPIOS}

Segundo Chrispino, existem diversos teóricos que conceituam de distintas formas as políticas públicas e, neste contexto, ele defende que o conceito de políticas públicas é resultado de inúmeras variáveis. As políticas públicas podem ser determinadas pelo critério de distinção quanto aos valores, às ideologias, aos contextos da ética, entre outros fatores e, isto faz com que observemos os desempenhos que os mais diversos formuladores exercem ou fazem delas uma política pública que possibilite uma conexão de ações que contribuam para a solução de um problema na sociedade. Ou seja, "é mediante as políticas públicas que são distribuídos e redistribuídos bens e serviços sociais, em resposta às demandas da sociedade" (CHRISPINO, 2016, p. 20).

No nosso entendimento, a política pública é uma ação para resolver e solucionar um problema público que esteja afetando negativamente a sociedade, ou seja, política pública é uma ação concreta e efetiva que gerará a possibilidade da solução de um conflito público.

Podemos tomar como exemplo a seguinte situação: imaginemos que um determinado grupo de pessoas não esteja podendo se deslocar para seu local de trabalho devido a cidade ter crescido de forma rápida e desordenada e boa parte dos trabalhadores dessa cidade não tinham suas residências próprias, pois pagavam aluguel próximo dos seus locais de trabalho. E que em determinada época houve a possibilidade de conquistar sua casa própria através de financiamento por um por programa do Governo Federal, porém este empreendimento fica distante quinze quilômetros dos locais de trabalho da maioria dos que ali passam a residir. No exemplo citado, fica claro que existe um problema público a ser enfrentado que é a maior distância daqueles trabalhadores de suas residências até seus locais de trabalho. Neste sentido deve haver uma definição de agenda, a formulação da política pública, a tomada de decisão, a implementação e a avaliação da política pública.

Portanto, levando em consideração esses processos, é possível que haja uma solução para o problema apresentado que, no caso do exemplo acima, seria a política pública de 
transporte público coletivo, política esta que se encontra inserida no contexto de uma política pública que deve ser resolvida no âmbito do município e para isto necessita de recurso para a execução deste serviço público e este recurso vem essencialmente dos tributos.

Tributos existem, fundamentalmente, para viabilizar o cumprimento das funções do Estado. É com a arrecadação tributária que se gera a maior parte das receitas públicas, indispensáveis para o custeio das finalidades estatais. Pode-se dizer, assim, que os tributos constituem o preço para o próprio funcionamento da engrenagem do Estado (ASSUNÇÃO, 2010, p. 13).

Deste modo, os tributos são revertidos para que o estado exerça suas funções e entre essas existe a da execução das políticas públicas que tomam forma por meio de gasto público direto. Grande parte desses investimentos passaram, ao logo do tempo, a serem responsabilidades dos municípios, pois, como já destacamos acima, são nas cidades que as pessoas vivem e são nelas que são formuladas e implementadas as mais diversas políticas públicas de saúde, educação, habitação, segurança, alimentação, trabalho, lazer, proteção à maternidade e à infância, ou seja, os direitos fundamentais que são garantidos no texto constitucional. Portanto, "as políticas públicas, seriam então ações políticas elaboradas e sistematizadas não voltadas para situações particulares ou destinadas para um determinado grupo de pessoas, mas orientada para o bem comum ou interesse público" (CABRAL, 1999, p. 132).

Como já destacado, as políticas públicas no âmbito dos municípios brasileiros tem sido cada vez mais reconhecidas e ressaltadas como componente estratégico para o desenvolvimento de ações que resultem em um efetivo respeito aos direitos fundamentais. Neste sentido, Nelson Saule Júnior destaca que:

O fortalecimento do papel do poder local para enfrentar os problemas urbanos como o desemprego, a degradação ambiental, a exclusão social, tornou-se um dos novos paradigmas no processo de globalização para a promoção do desenvolvimento sustentável nas cidades (SAULE JÚNIOR, 2001, p. 17).

Este fortalecimento dos municípios não veio em conjunto com a possibilidade do poder de tributar, pois como destaca Leonam Lizieiro, existem "as limitações legais ao poder de tributação dos governos subnacionais (em especial os Municípios) e a sua crescente responsabilização sobre a gerência de serviços públicos e sociais” (LIZIERO, 2020, p. 134). 
Neste mesmo sentindo, Maria de Fátima Ribeiro destaca que "alguns municípios dependem praticamente dos repasses dos governos estaduais e federal para executar políticas públicas" (RIBEIRO, 2016, p. 331). Para reforçar esta premissa.

Como o poder de manobra tributária é indiscutivelmente menor nos Municípios, haja vista o regime constitucional das competências tributárias, há, quase sempre, um verdadeiro descompasso entre as possibilidades financeiras dos Municípios e a viabilidade de concreção do seu expressivo rol de competências administrativas, melhor dizer, de imposições constitucionais relativas à promoção de prestações positivas na sociedade (CAVALCANTE; LIMA, 2015, p. 136).

Deste modo, o federalismo fiscal tem um papel importante para a elaboração e a execução de políticas públicas e um dos principais financiadores destas políticas são feitos por meio do Fundo de Participação dos Municípios. Este fundo é composto por recursos oriundos do IPI e do IR conforme determina o comando do artigo 159 da Carta Federal, que destaca que do montante arrecado desses impostos, 22,5\% é destinado ao FPM, assim:

Art. 159. A União entregará:

I - do produto da arrecadação dos impostos sobre renda e proventos de qualquer natureza e sobre produtos industrializados quarenta e oito por cento na seguinte forma:

a) vinte e um inteiros e cinco décimos por cento ao Fundo de Participação dos Estados e do Distrito Federal;

b) vinte e dois inteiros e cinco décimos por cento ao Fundo de Participação dos Municípios;

c) três por cento, para aplicação em programas de financiamento ao setor produtivo das Regiões Norte, Nordeste e Centro-Oeste, através de suas instituições financeiras de caráter regional, de acordo com os planos regionais de desenvolvimento, ficando assegurada ao semi-árido do Nordeste a metade dos recursos destinados à Região, na forma que a lei estabelecer;

d) um por cento ao Fundo de Participação dos Municípios, que será entregue no primeiro decêndio do mês de dezembro de cada ano.

Deste modo, é oportuno entender o comando constitucional ao falar que a União entregará, pois este comando legislativo é claro ao determinar que o ente federal entregue aos entes municipais o montante devido ao FPM. Portanto, é perceptível, a partir de um olhar 
atento no texto constitucional, a carência financeira dos municípios, pois estes dependem da entrega, por parte do governo central, de parte do que é arrecado por este, deixando, deste modo, os entes municipais dependentes do ente federal.

\section{OS INCENTIVOS FISCAIS PÓS-CRISE DE 2008 E O RECURSO EXTRAORDINÁRIO 705.423}

Com a crise de 2008 que surgiu nos Estados Unidos da América houve um efeito que terminou afetando vários países, entre estes o Brasil, que "diante de um cenário de incertezas, o crédito tornou-se escasso, abalando o consumo" (ASSUNÇÃO, 2010, p. 26). Para evitar uma crise ainda maior, o Governo Federal tomou medidas de incentivo fiscal visando à retomada do crescimento, foram reduzidas as alíquotas do IPI, IR e IOF para que o consumo fosse estimulado na área automobilística, eletrodomésticos da linha branca, materiais de construção e bens de capital.

A política fiscal adotada pelo governo federal para superar as ameaças da crise pode
se revelar um fator de sucesso, criando ambientes favoráveis ao desenvolvimento
econômico. Entretanto, também pode gerar desequilíbrios reflexos no arranjo
financeiro do federalismo brasileiro, comprometendo a saúde das contas públicas de
entes subnacionais e ameaçando a continuidade de programas sociais (ASSUNÇÃO,
2010, p. 05).

Esta política fiscal adotada pelo Governo Federal de incentivo gera consequentemente a redução considerável da arrecadação tributária relacionada ao IPI e ao IR que impacta diretamente nos valores das transferências constitucionais aos estados e aos municípios, no caso deste último, o FPM que é um dos fundos que possibilita ser um dos maiores montantes de financiamento de políticas públicas.

Uma das principais questões levantadas por estudiosos quanto à política fiscal centralizadora nas mãos do ente nacional é que, ao lado do poder de tributar, a União detém o poder de desonerar através da concessão de incentivos fiscais, pois o poder de desonerar é inerente ao poder de tributar.

Uma das principais críticas formuladas à concepção de normas tributárias indutoras repousa no fato de geralmente não existirem critérios intranormativos, ou seja, integrantes da própria estrutura da norma jurídica, que possam expressar a finalidade visada (ASSUNÇÃO, 2010, p. 16). 
Como destacado acima, podemos dizer que de um lado são expressos na Constituição Federal de 1988 diversos limites ao exercício do poder de tributar, porém não ocorre o mesmo ao poder de desonerar, pois existe uma linha vaga e poucas ressalvas expressas quanto aos incentivos fiscais possíveis ou não de serem realizados pelo ente nacional. O próprio Supremo Tribunal Federal tem uma jurisprudência considerável com precedentes a respeito das limitações constitucionais ao poder de tributar, porém no tocante aos parâmetros de controle do poder de desonerar são escassas as decisões neste sentido de extrafiscalidade.

Através do Recurso Extraordinário $n^{\circ}$ 705.423, o Município de Itabi, em Sergipe, contesta acórdão do Tribunal Regional Federal da $5^{\text {a }}$ Região, que negou àquele Município o direito de receber os valores que não tenham sido recolhidos devido à concessão de isenções fiscais de IPI e Imposto de Renda. O referido TRF da $5^{\circ}$ Região, analisando o provimento da apelação, entendeu que a competência tributária da União para instituir Imposto de Renda e Imposto Sobre Produtos Industrializados não poderia sofrer restrições em decorrência do repasse de parte do produto da arrecadação dos tributos ao Fundo de Participação dos Municípios.

O pleito do recorrente era no sentido de que o montante do FPM para cálculo de cota parte do município não poderia implicar em redução das parcelas oriundas da concessão de benefícios e incentivos fiscais por parte da União sobre o IR e o IPI, pois fere o artigo 159, I, 'b' e 'd' da nossa Carta Federal.

O questionamento inserido no RE $n^{\circ} 705.423$ é oportuno verificar se há limites para a União isentar os tributos de sua competência, deste modo, quais são as garantias constitucionais para o Município exigir o cumprimento por parte da União, quanto ao repasse do Fundo de Participação do Município? Já ao prover pela Repercussão Geral do Recurso Extraordinário, o ministro Ricardo Lewandowski, Relator da Repercussão Geral, entendeu que a discussão é de extrema importância do ponto de vista econômico, jurídico e político. No sentido de delimitar seu alcance constitucional, o referido Ministro, manifestou-se no sentido de que:

A questão constitucional versada neste recurso consiste em definir, sob o prisma constitucional, até que ponto a concessão de benefícios e incentivos fiscais relativos ao Imposto de Renda e ao Imposto Sobre Produtos Industrializados pode impactar nos valores transferidos aos Municípios a título de participação na arrecadação 
daqueles tributos (STF, Repercussão Geral do Recurso Extraordinário 705.423, Relator: Ministro Ricardo Lewandowski, Brasil, 2013, p. 02).

Já na decisão do Recurso Extraordinário é muito óbvia a constitucionalidade da concessão de incentivos, benefícios e isenções fiscais, podendo, inclusive, a união não repassar aos demais entes a cota do que foi isentada conforme é destacado em sua tese jurídica que diz que "é constitucional a concessão regular de incentivos, benefícios e isenções fiscais relativos ao Imposto de Renda e Imposto sobre Produtos Industrializados por parte da União em relação ao Fundo de Participação de Municípios e respectivas quotas devidas às Municipalidades" (STF, Recurso Extraordinário 705.423, Relator: Ministro Edson Fachin, Brasil, 2016, p. 02).

Passamos agora a transcorrer sobre as razões dos votos dos ministros do STF no referido Recurso Extraordinário, sendo que seu relator, o Ministro Edson Fachin adotou como expediente argumentativo neste voto, três eixos de raciocínio. Primeiro, a compreensão e premissas a respeito dos municípios no federalismo fiscal brasileiro, trazendo dois fenômenos políticos relevantes para a contextualização do litígio constitucional em concreto que são a municipalização das receitas e despesas públicas que no longo prazo, só os municípios ganharam espaço relativo na federação brasileira e o segundo fenômeno é a significativa criação de municípios na primeira década de vigência da Constituição da República de 1988.

O segundo raciocínio é quanto ao arquétipo constitucional das competências e autonomias financeiras dos entes federativos, pois o próprio Ministro concorda que as assimetrias sociais e regionais geram uma injustiça na forma que se encontra o dispositivo constitucional do termo "produto da arrecadação" que é o montante que deve ser direcionado aos demais entes da federação, porém, o mesmo Ministro destaca que não pode ir à contramão do que se tem descrito na Constituição, pois não cabe ao STF decidir ao contrário do que se tem na Carta Maior respeitando-se, deste modo, o Estado Democrático de Direito. O terceiro argumento utilizado pelo Relator é sobre os reflexos jurídicos desse paradigma fiscal no conteúdo e no cálculo do Fundo de Participação dos Municípios. Portanto, são estas três premissas principais que levaram o Ministro Relator a decidir pela rejeição do Recurso Extraordinário ora analisado.

O Ministro Luís Roberto Barroso acompanhou o voto do relator, pois entende que a competência para arrecadar, no caso julgado, é da União, bem como para conceder isenções, 
porém destacou que existe uma assimetria fiscal que é injusta nos moldes que existem hoje e que a crise fiscal que assolou o país naquele momento deveria ter servido para que ajustes constitucionais pudessem modificar a forma de repartição dos tributos já que existe, segundo ele, uma concentração de arrecadação da União em detrimento dos estados e munícipios, mas que isto deve ser realizado pelo Congresso Nacional e não pelo Supremo.

Acompanhando integralmente o voto do Relator, o Ministro Teori Zavascki acrescentou que "as desonerações fiscais, de um modo geral, são atribuídas também para promover o desenvolvimento econômico que, por sua vez, gera maior arrecadação tributária e que, portanto, aumenta a participação dos Estados e dos Municípios nessa arrecadação futura". Além disto, observa que o IPI tem finalidade extrafiscal e que se retirar a administração deste da União fere a própria natureza constitucional deste imposto.

A Ministra Rosa Weber e o Ministro Celso de Mello acompanharam o Relator sem tecer mais comentários, destacado, apenas, que tem dúvidas quanto à matéria. Já o Ministro Luiz Fux abriu divergência do voto do Relator com uma abordagem bem extensa. Dentre os argumentos estão o do federalismo fiscal brasileiro e a importância das participações no produto da arrecadação, para fins de garantia da autonomia financeira dos municípios, onde, o mesmo traça um panorama histórico do federalismo brasileiro chegando à conclusão de que há centralização fiscal na União em detrimento dos demais entes da federação e que deve haver uma participação na arrecadação federal, por parte dos entes subnacionais, para reparar as desigualdades existentes no Brasil.

Outro argumento utilizado pelo Ministro que divergiu do Relator é sobre a política desonerativa da União em relação ao IR e ao IPI e seus impactos nas finanças dos municípios, discorrendo que na análise do RE 572.762 de 2008, embora tenha sido sobre fato diverso do RE 705.423, os fundamentos jurídicos utilizados naquele poderiam ser usados neste. Portanto, para o Ministro não há dúvidas de que cabe ao Tribunal Constitucional, no exercício da jurisdição constitucional, a mediação do presente conflito federativo, atuando em prol da garantia da autonomia dos entes federados, elemento essencial de uma República Federativa, preservando, deste modo, o Estado Democrático de Direito.

Nesta mesma linha, o Ministro Dias Toffoli segue divergindo do voto do Relator alegando que este tem uma linha teórica plausível, mas que o contraditório é fundamental, 
entendendo que houve abuso e exageros na lide em questão por parte da União. Defendendo as linhas de raciocínio dos dois votos que divergem do Relator, o Ministro Ricardo Lewandowski, seguiu o Relator em virtude de não ser possível ir de encontro, do ponto de vista lógico, contra a Constituição. Um ponto que nos chama atenção no voto deste Ministro é quando o mesmo reconhece que não existe um federalismo no Brasil, pelo menos do ponto de vista fiscal, pois, segundo ele, existe no Brasil um Estado Unitário descentralizado.

Os ministros Gilmar Mendes, Marco Aurélio e a Ministra Presidente Cármen Lúcia votaram pela recusa do recurso, porém reconheceram, assim como outros ministros que foram por esta linha, que é preciso repensar o modelo federativo vigente no país, mas que a Constituição em se artigo 159 é muito clara sobre o tema tratado no Recurso Extraordinário.

Embora o STF tenha decidido por nove votos a dois, contrário ao Recurso Extraordinário interposto pelo município de Itabi-SE, entendemos que, conforme destaca o artigo 159, inciso I da Constituição, a União deverá entregar 49\% da arrecadação do IPI e do IR para entes federativos e fundos constitucionais, restando-lhe apenas $51 \%$ do montante arrecadado. A União não pode fazer renúncia fiscal além desses $51 \%$, que é a parte que lhe cabe da arrecadação, seja sob a forma de incentivo, isenção ou política anticíclica.

Em artigo publicado no site do Consultor Jurídico, Alexandre Silveira e Fernando Scaff mostram os principais aspectos que foram considerados pelos ministros, quando da análise da decisão do STF em outro Recurso Extraordinário, desta feita, o 572.762, de 2008, em que litigaram o município de Timbó e o estado de Santa Catarina sobre a repartição de rendas tributárias com a concessão de incentivo fiscal do ICMS.

[a] deve ser preservada a autonomia financeira do município, vedando qualquer condicionamento ao repasse constitucional, e assim efetivando a autonomia política; [b] o valor a ser repassado sequer constitui receita do ente arrecadante; [c] este não pode livremente dispor da arrecadação, sob pena de ofensa ao pacto federativo; [d] o estado-membro, ao instituir benefício fiscal que reduz a arrecadação, atingindo a parcela de repasse aos municípios, faz "cortesia com o chapéu alheio", na expressão do ministro Ricardo Lewandowski; [e] os incentivos fiscais devem ser instituídos com exclusão da parcela de repartição tributária; e [f] há um condomínio federativo no plano das receitas, para sustentar a autonomia tributário-financeira dos municípios, e assim suportar sua autonomia político-administrativa (SILVEIRA; SCAFF, 2009). 
Deste modo, é perceptível que houve uma mudança de entendimento da Suprema Corte brasileira que prejudicou os entes subnacionais e em especial os munícipios. Portanto, embora os incentivos fiscais dados sobre o IPI e o IR no período da crise iniciada em 2008 pudessem ser considerados coerentes com a regra da proporcionalidade não constituem, porém, a ausência de reflexos financeiros negativos das medidas adotadas pelo ente federal sobre o equilíbrio das finanças públicas dos entes subnacionais.

\section{CONSIDERAÇÕES FINAIS}

Embora este artigo não tenha finalidade de esgotar a temática ora abordada, entendemos que chegamos as seguintes conclusões, apontando-se, em alguns momentos, caminhos que podem ser percorridos para que de fato tenhamos um equilíbrio no pacto federativo brasileiro:

- Existe, a partir das referências incluídas nesta pesquisa, que o federalismo fiscal no Brasil é verticalizado e centralizado no poder da União Federal em detrimento dos demais entes federativos;

- O Município é um ente federal dos mais importantes do sistema federativo brasileiro, pois é lógico a sua inclusão no texto da Carta de 1988 como ente federal, porém, entendemos também que existe uma complexidade quanto a esta inserção, já que, o caso brasileiro é diverso dos demais modelos federativos, tendo o Município como ente federal sem a representação necessária no parlamento já que o Senado Federal é a casa legislativa, onde se defende os interesses dos entes estaduais membros da federação;

- Evidenciou-se que a decisão no recurso extraordinário 705.423, embora tenha fundamento constitucional, provocou um conflito axiológico, pois as normas tributárias indutoras, que são as alterações das alíquotas do IPI e do IR, tem a finalidade de estimular a demanda interna, de modo a garantir a manutenção do nível de empregos e o desenvolvimento econômico, como foi no caso das politicas fiscais empregadas para conter os efeitos da crise de 2008. Porém, por outro lado, os reflexos das normas no sistema de repartição de receitas tributárias, ocasiona a redução considerável de repasses aos municípios e, em consequência, o comprometimento para a execução de políticas públicas que tem a finalidade de efetivar de direitos fundamentais; 
- Conclui-se que as políticas fiscais que são centralizadas na União produzem impactos severos e contínuos nas receitas dos entes subnacionais e que é preciso haver uma prévia discussão com os três entes da federação, buscandose um denominador comum, a fim de impedir que decisões centralizadas não ocasionem a perda de autonomia financeira das unidades descentralizadas, evitando, assim, um abalo nos pilares da cooperação federativa;

- É preciso que haja compensações financeiras satisfatórias para corrigir as assimetrias negativas geradas pelas concessões de benefícios e incentivos fiscais, preservando os pilares do federalismo fiscal nos caso do emprego de normas tributárias indutoras pela União que acarrete situações de desequilíbrio no arranjo de repartição de receitas com os entes subnacionais;

- É preciso alterar a legislação para que os incentivos e concessões fiscais restrinjam-se apenas a parte do produto da arrecadação tributária pertinente aos estados e à União, preservando-se a parcela destinada aos municípios, garantindo-se, assim, o equilíbrio federativo;

- Deve-se haver uma participação dos municípios nas competências constitucionais que são, como vimos neste artigo, centralizadas no ente Federal, a fim de garantir uma maior repartição das receitas públicas nacionais que supere esta distorção na federação brasileira;

Portanto, é preciso encarar a possibilidade de mudança no pacto federativo brasileiro que vem sendo negado nas decisões das cortes julgadoras e que foi denegada na elaboração da Constituição de 1988, embora esta tenha o federalismo como princípio basilar na sua constituição para que possamos ter uma concretização dos direitos fundamentais dispostos na mesma Constituição, tendo os entes federados igualdade nas suas possiblidade de tributar.

\section{REFERÊNCIA BIBLIOGRÁFICA}

ASSUNÇÃO, Matheus Carneiro. Incentivos Fiscais e Desenvolvimento Econômico: a função das normas tributárias indutoras em tempos de crise. In: Finanças Públicas - XV Prêmio Tesouro Nacional. 2010.

CABRAL, Edgar Araújo. Política pública: o que é e como se faz. In: Sistema de garantia de direitos. Um caminho para a proteção integral. Recife: CENDHEC, 1999. 
CAVALCANTE, Denise Lucena; LIMA, Raimundo Márcio Ribeiro. Ilusão do pacto federativo cooperativo e os custos dos direitos sociais. Nomos: Revista do Programa de PósGraduação em Direito da Universidade Federal do Ceará. Fortaleza, v. 35.1, jan./jun. 2015.

CERTEAU, Michel de. A invenção do cotidiano: a arte de fazer. Tradução de Ephraim Ferreira Alves. 22. Ed. Petrópolis: Editora vozes, 2014.

CHRISPINO, Alvaro. Introdução ao Estudo das Políticas Públicas: Uma visão interdisciplinar e contextualizada. 1.ed. Rio de Janeiro: FAPERJ/FGV, 2016. V.1.

CONCI, Luiz Guilherme Arcaro. Impacto da pandemia da COVID-19 na federação brasileira - descentralizando a disfuncionalidade. IN: $O$ direito público em tempos pandêmicos: 9 países, 11 trabalhos e uma porção de inquietudes / Organizador Luiz Guilherme Arcaro Conci. 1. Ed. - São Paulo: Tirant lo Blanch, 2020.

FERRAZ JUNIOR, Tércio Sampaio. Competência tributaria municipal. In: Direito Tributário Atual. Vol11/12, São Paulo, Editora Resenha Tributária, 1992.

HORTA, Raul Machado. Direito Constitucional. $4^{\text {a }}$ edição. Belo Horizonte: Editora Del Rey, 2003.

LEITE, Geilson Salomão. O ICMS do Estado Federal Brasileiro. In: Constituição, política e cidadania. 01. ed. Patos: GIW Editora, 2013.

LIZIERO, Leonam; ZILLI, Tiago. Críticas ao pacto federativo brasileiro: assimetria de direito, municipalismo e antagonismo do federalismo fiscal. In: RFD-Revista da Faculdade de Direito da UERJ. [S.1.], n. 38, p. 122 - 138, fev. 2020.

LIZIERO, Leonam Baesso da Silva. O federalismo no império brasileiro: da Constituição de 1824 ao Ato Adicional de 1834. IN: Revista Diorito, v. 1, n. 1, p. 112-124, jul./dez.2017.

RIBEIRO, Maria de Fátima. Concessão de incentivos fiscais pela união e os reflexos nos valores repassados ao fundo de participação dos municípios. In: Revista do Programa de PósGraduação em Direito da UFC. v. 36.2, jul./dez. 2016.

SAULE JÚNIOR, Nelson. Políticas Públicas Locais: Município e Direitos Humanos. In: BUCCI, Maria Paula Dallari. Direitos humanos e políticas públicas. São Paulo, Pólis, 2001. 
SILVA, José Afonso da. Curso de Direito Constitucional Positivo. 9a ed. São Paulo, Malheiros, 1993.

SILVEIRA, Alexandre Coutinho da; SCAFF, Fernando Facury. Prefeituras podem exigir ressarcimento no FPM. IN https://www.conjur.com.br/2009-out-02/prefeituras-podem-exigirvolta-beneficios-fiscais-dados-uniao. 2009.

YIN, Robert K. Estudo de caso: planejamento e métodos. Tradução de Daniel Grassi. 2. ed. Porto Alegre: 2001. 